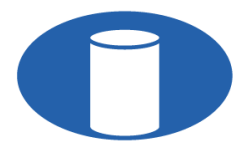

IBRACON Structures and Materials Journal

Revista IBRACON de Estruturas e Materiais

IBRACON

ISSN 1983-4195 ismj.org

ORIGINAL ARTICLE

\title{
Analysis of mortar coating with different types and proportions of chemical admixtures that have water retentivity properties
}

\section{Análise de argamassas de revestimento com variação do tipo e concentração de aditivos com propriedades retentoras de água}

\author{
Alessandra Tolentino Souza ${ }^{\mathrm{a}}$ \\ Catharina de Almeida Carvalhais ${ }^{\mathrm{a}}$ \\ White José dos Santos ${ }^{\mathrm{a}}$ (i)
}

${ }^{a}$ Universidade Federal de Minas Gerais - UFMG, Departamento de Engenharia de Materiais e Construção, Belo Horizonte, MG, Brasil

Received 7 May 2020

Accepted 15 January 2021

\begin{abstract}
Water retaining agents are the main admixtures used to retain water against evaporation and substrate suction, and there are several chemical compounds for this purpose. To deepen the knowledge of mortar admixtures, several concentrations $(0 \%, 1.5 \%, 5 \%, 10 \%$ and $15 \%)$ of three different types of admixtures were studied: an acrylic polymer, a cellulosic and ethylene vinyl acetate. Fresh properties (consistency, water retention, density and incorporated air), physical indexes (density and porosity) and compressive strength at 28 days were analyzed. It has been found that admixtures can act in different ways on mortars depending on the type of chemical agent used and can significantly affect the mechanical and durability characteristics in the fresh and hardened state. With this work it was verified the importance of searching references about the influence of chemical compounds before using it.
\end{abstract}

Keywords: coating mortar, water retaining, admixture proportion, performance.

\begin{abstract}
Resumo: Os retentores de água são os principais aditivos utilizados para reter água frente a evaporação e a sucção do substrato, existindo diversos compostos químicos para essa finalidade. Com o intuito de aprofundar os conhecimentos dos aditivos nas argamassas, estudou-se várias concentrações $(0 \%, 1.5 \%, 5 \%, 10 \%$ e $15 \%)$ de três tipos diferentes de aditivos: um polímero acrílico, um celulósico e um polímero de acetato vinil etileno. Foram analisadas propriedades no estado fresco (consistência, retenção de água, densidade e ar incorporado), índices físicos (densidade endurecida e porosidade) e a resistência à compressão com 28 dias. Verificou-se que os aditivos podem atuar de diversas formas nas argamassas dependendo do tipo de agente químico utilizado, podendo afetar significativamente as características mecânicas e de durabilidade no estado fresco e endurecido. Com o trabalho, verificou-se a importância de buscar referências sobre a influência dos compostos químicos antes da utilização.
\end{abstract}

Palavras-chave: argamassa, retentor de água, proporção dos aditivos, performance.

How to cite: A. T. Souza, C. A. Carvalhais, and W. J. Santos, "Analysis of mortar coating with different types and proportions of chemical admixtures that have water retentivity properties," Rev. IBRACON Estrut. Mater., vol. 14, no. 6, e14602, 2021, https://doi.org/10.1590/S198341952021000600002

\section{INTRODUCTION}

Water retaining agents are widely used on coating mortars, mainly, to retain water during the dehydration process caused by substrate suction or caused by evaporation into the atmosphere due to climate agents [1], [2]. These phenomena may result in an inefficient hydration of cementitious compounds, decreasing mechanical and durability properties of mortars [3]-[5].

Corresponding author: White José dos Santos. E-mail: white.santos@demc.ufmg.br

Financial support: None.

Conflict of interest: Nothing to declare. 
The best known and most used water retaining admixture are cellulose ethers: Hydroxypropyl methyl cellulose (HPMC/MHPC), hydroxyethyl methyl cellulose (HEMC/MHEC), hydroxyethyl cellulose (HEC), hydroxypropyl cellulose (HPC), methyl cellulose (MC) [2], [5]-[7]. However, there are other types of compounds used for this function, such as Superabsorbent polymers (SAP), a polymeric group capable of retaining part of the kneading water, which is gradually released during the hydration process [6]; guar ether; starch ether [8]; natural gums, silica fume and bentonite.

Current research indicates that depending on the type of admixture used, there may be great variability in their properties' results [9], [10], even with compounds with the same chemical name [11]. Viscosity, molar mass and/or nature and quantity of chemical substitution groups can be responsible for these variations [12]. For example, the increase in the molar mass of an additive can directly affect the increase in mortar viscosity [13]. It is important to note that water retainers can act differently in cement mortars (cement: sand: water) and mixed mortars (cement: hydraulic lime: sand: water) [8]. On mixed mortars, the excessive water or trapped water can prevent $\mathrm{CO}_{2}$ from penetrating the mortar, slowing carbonation process [13]-[15]. Studies showed that the same type of cellulosic (HPMC) can present different percentages of water retention, according to the length of the molecular chain of the additive used and the dosage [16], [17]. This variation could reach up to $14 \%$ when comparing different types of cellulosic products [13]. The more water retaining added to the mixture, greater the ability to incorporate air of mortar [8]. With the incorporated air increase, density [17] and mechanical resistance of the mortar decrease since pores are weakening points of the material. The lower elastic modulus is also related with the increase in the air incorporation [8] and it can be favorable in reducing pathologies due to structural deformations or land settlement [16]. The water retainer also affects, secondarily, by slowing the setting of the cement, because, inorganic compounds, such as cellulose ether, added to cement paste demonstrate affinity to cement hydration products [18].

Due to the exposed facts, it is important to know the chemical additive which will be added to the mortar, or even carry out a previous analysis of the influence of it on mortar's properties to achieve the desired results of designed properties [9]. This study intended to research the properties of three different types of admixtures with potential to act as a water retainer: hydroxyethyl methyl cellulose (HEMC), vinyl acetate and ethylene polymer (pAVE) and acrylic polymer (pA), varying their content (including over dosage). HEMC is a hydroxyethyl methyl cellulosic commonly used in mortars for its excellent water retention at low dosage [19]. It could also be used in fiber cement, fine mortars (adhesive) and adhesives for cement-based tiles. pAVE is a copolymer of vinyl acetate and ethylene [20] dispersible in water and it has good resistance to saponification. Its main activities are in improving adhesion, flexural strength, deformability, abrasion resistance, maximizing its use in adhesive mortars, grouts and plasterboards glues. However, studies [21], [22] showed the potential of this admixture for use as water retainer.

$\mathrm{pA}$ is a polymeric adhesive based on acrylic for stabilized and productive mortars [23] generally used in plastering and masonry laying, stabilized light mortars, smoothing and filling layers, and mortars for underlay. It tends to improve the adherence of the mortar on the substrate, the workability, the water retention, the cohesion and thereby reduce the shrinkage cracks [23].

These three admixtures are marketed as water retainers, however, though previous research [9], [10] it was identified that some did not have enough retention. It is also important to note that the dosages are variable in the research [2], [5]-[8], [13], [18], [21], [22], and because of this it can generate different influences on mortars. Therefore, it was decided to carry out this research to investigate the dosage and efficiency of each admixture exposed. Most studies of admixtures are in concrete or micro concrete for structural purposes, there are few references with typical situations of coating mortars (thin layer subjected to substrate suction and insolation), so it is essential to verify how each admixture behaves in coating mortar as regards properties in fresh and hardened state, so more suitable coating mortars can be used. Therefore, this study tended to establish a comparison between the admixtures, highlighting the differences and similarities between each one in properties in the fresh state: consistency, fresh state density and water retention; physical indexes: density in the hardened state, theoretical incorporated air and theoretical porosity; and compressive strength at 28 days. It was also proposed, when it was possible, equations for approximating the behavior of each mortar.

\section{MATERIALS AND EXPERIMENTAL PROGRAM}

The cement used was CP II-F 32 (Brazilian ordinary Portland cement with 10\% addition of limestone powder), of chemical and physical composition expressed in Table 1, with specific gravity of $3100 \mathrm{~kg} / \mathrm{m}^{3}$ and bulk density of $1700 \mathrm{~kg} / \mathrm{m}^{3}$. 
Table 1. Chemical and Physical characteristics of cement and hydraulic lime

\begin{tabular}{|c|c|c|c|c|c|c|c|c|c|}
\hline Material & $\mathrm{SiO}_{2}(\%)$ & $\mathrm{Al}_{2} \mathrm{O}_{3}(\%)$ & $\mathrm{Fe}_{2} \mathrm{O}_{3}(\%)$ & $\mathrm{CaO}(\%)$ & MgO (\%) & $\begin{array}{l}\text { LOI } \\
(\%) \\
\end{array}$ & $\begin{array}{c}D_{10} \\
(\mu \mathrm{m})\end{array}$ & $\begin{array}{c}D_{50} \\
(\mu \mathrm{m})\end{array}$ & $\begin{array}{c}D_{90} \\
(\mu \mathrm{m})\end{array}$ \\
\hline Cement & 18.97 & 4.21 & 2.81 & 64.52 & 2.01 & 5.21 & 5.3 & 22 & 63 \\
\hline Hydraulic Lime & 1.88 & 0,26 & 0.22 & 49.35 & 26.45 & 21.74 & 0.47 & 4.28 & 30.84 \\
\hline
\end{tabular}

This type of cement was chosen because it does not have potentially reactive mineral additions that can affect the behavior of admixtures. The hydraulic lime was used to assess whether the retention measurement time influenced this parameter. Was used Brazilian CH I, with physical and chemical composition expressed in Table 1, with specific mass of $2800 \mathrm{~kg} / \mathrm{m}^{3}$ and bulk density of $800 \mathrm{~kg} / \mathrm{m}^{3}$. This hydraulic lime has certification of $0 \%$ of non-hydrated oxides in its composition, according to the supplier. The sand used was natural quartz sand from the riverbed: well graded, its main characteristics are shown in Table 2 and Figure 1.

The chemical composition was determined by X-ray fluorescence (XRF) and loss on ignition was determined by calcination of the sample at $405{ }^{\circ} \mathrm{C}$ and/or $1000{ }^{\circ} \mathrm{C}$, using the method PHY01E: LOI (Loss on ignition). To determine the particle size distribution of the material a laser diffraction granulometer (Sympatec Helos 12LA) was used along with a $50 \mathrm{~mm}$ lens and $0.05 \%$ sodium hexametaphosphate dispersant. In addition, a helium gas pycnometer (Quantachrome SPY-3) was used to determine the specific mass of the material.

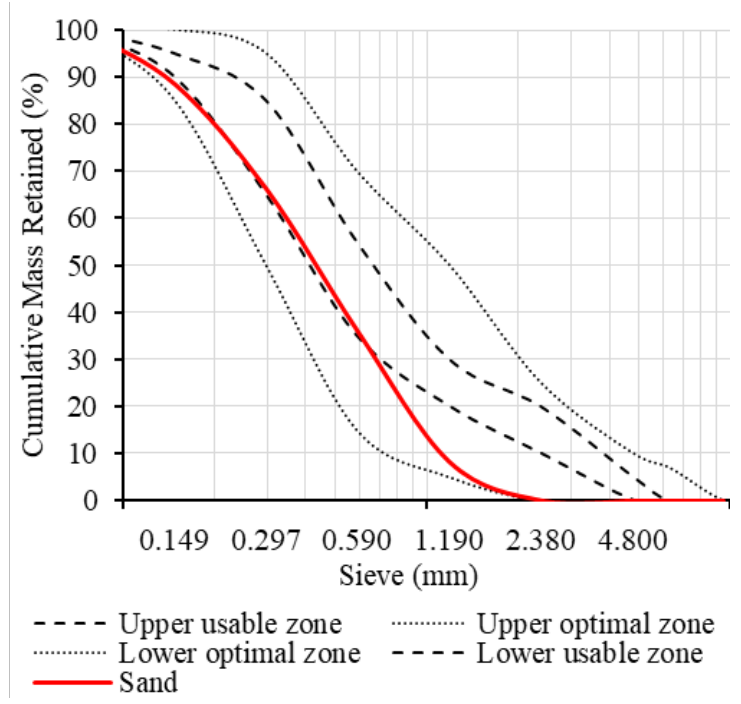

Figure 1. Fine aggregate particle size distribution.

Table 2. Fine aggregate characteristics

\begin{tabular}{cc}
\hline & Fine aggregate \\
\hline Specific gravity $\left(\mathrm{kg} / \mathrm{m}^{3}\right)$ & 2584 \\
\hline Bulk density $\left(\mathrm{kg} / \mathrm{m}^{3}\right)$ & 1283 \\
\hline Fineness Modulus & 1.995 \\
\hline Maximum diameter $(\mathrm{mm})$ & 2.4 \\
\hline
\end{tabular}

The mix proportion adopted for the analyzed mixtures was 1:5:1.83 (cement: sand: water by volume), according to the prescriptions established in Santos' methodology [24] which considered the amount of binder according to the voids between the aggregate particles, stablished through the characteristic's distribution of cement and sand. The proportions of admixtures used were $0 \%$ (reference, without admixture), 1.5\%, 5\%,10\% and 15\% in relation to the cement mass for each type of admixture: acrylic polymer (pA), vinyl acetate polymer and ethylene (pAVE) and hydroxyethyl methyl cellulose (HEMC). The proportions adopted were chosen due to the correlations established with the proportions found in the literature and through manufactures' specifications for the studied admixtures [19], [20], [23], [25]. The main characteristics of admixtures 
are shown in Table 3, the density of cellulosic ether is not specified in the product's technical sheet. The amount of water used was $15.26 \%$ of the total dry material, and came from public supply, which is acceptable for use in the dosage of cementitious materials without requiring prior analysis, according to NBR 15900-1 [26].

Table 3. Admixture's characteristics

\begin{tabular}{cccc}
\hline Name & Density $\left(\mathbf{K g} / \mathbf{m}^{\mathbf{3}}\right)$ & Type & Chemical base \\
\hline pA & 1000 & Liquid & Acrylic polymer \\
\hline pAVE & 540 & Powder & Vinyl acetate and ethylene polymer \\
\hline HEMC & - & Powder & Hydroxyethyl methyl cellulose \\
\hline
\end{tabular}

Two of the three admixtures used were in powder form and therefore must be previously added with dry materials (cement and sand). So, they were mixed for 30 seconds and then water was added, continuing the mixing process for another 3 minutes. For mixing the acrylic polymer, as it is in liquid form, it must be diluted in part of the mixing water. Therefore, first the cement and sand were added and mixed for 30 seconds, then the water and the diluted admixture were added, and the mixing procedure continues for more 3 minutes. All mixing processes occurred for 3 minutes and 30 seconds in total.

After the mixing process, the mortars were testes on the Flow-Table [27] to obtain consistency. And water retention was obtained through NBR 13277 [28], measuring the capacity of the mortar to retain water under the action of suctioning paper filters under the pressure of a standardized weight of $2 \mathrm{~kg}$. Mortar and paper filters were weighed with the aid of a $0.001 \mathrm{~g}$ precision balance. For each of the three polymers proportion were molded 3 samples of the same mortar-mix to obtain the results variability.

Regarding water retention, it was also analyzed whether the test measurement time can influence the results, so that the most appropriate retention value for the method used can be measured. For this comparation, a mixed mortar was used with proportion of 1.00:1.08:4.41:1.82 (cement: hydraulic lime: sand: water by volume), proportion from Souza's [29] previous research, which considered particle size of cement, sand and hydraulic lime. This proportion was compared with a cement mortar with $1.5 \%$ of acrylic polymer. The cement mortar was made using the same process as for powder admixtures [29], which considered characteristics of cement, sand and water, by same mix designer method of mortar without lime. It was water retention measures were made per time in 0, 15, 30 and 60 minutes.

The physical indexes analyzed were: density in the fresh and hardened state [30], theoretical incorporated air and theoretical porosity. The theoretical parameters were obtained through the relationship between the density of the materials used, without considering the voids, with the density in the fresh state (to obtain the theoretical incorporated air) and, to obtain the theoretical porosity, with density in the hardened state. The hardened specific mass method used four cylindrical samples $(5 \times 10) \mathrm{cm}$, for each mixture, which were kept for 24 hours in an electric oven at $(100 \pm 5)^{\circ} \mathrm{C}$ to remove any loose water, when the stability of the mas as verified. A precision balance weight of $0.01 \mathrm{~g}$ was used to measure the samples. The theoretical specific mass was acquired by the ratio of materials, cement $\left(\mathrm{m}_{\mathrm{c}}\right)$, sand $\left(\mathrm{m}_{\mathrm{s}}\right)$, admixture $\left(\mathrm{m}_{\mathrm{a}}\right)$ and water $\left(\mathrm{m}_{\mathrm{w}}\right)$, of a given volume of specimen $\left(\mathrm{v}_{\mathrm{c}}\right)$. The theoretical porosity was obtained through Equation 1, through the relation of hardened state density $\left(\mu_{\mathrm{h}}\right)$ and theoretical specific mass.

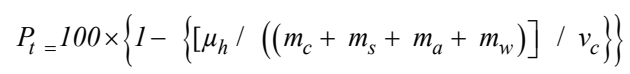

Compressive strength was evaluated according to NBR 7215 [31] with a loading rate of $(500 \pm 10) \mathrm{N} / \mathrm{s}$ in the EMIC DL $30000 \mathrm{~N}$ universal machine. The cylindrical samples to measure specific mass and compressive strength are $10 \mathrm{~cm}$ height and $5 \mathrm{~cm}$ diameter. Mortars were molded in two layers with 12 strokes in each one for a proper densification. After 48 hours of molding, the samples were unmolded and remained in laboratory environment, with an average temperature of $24{ }^{\circ} \mathrm{C}$ and relative humidity of $60 \%$ for more 26 days before testing density in the hardened state and compressive strength. 


\section{RESULTS AND DISCUSSIONS}

\subsection{Consistency}

All tested mixtures $(0 \%, 1.5 \%, 5 \%, 10 \%$ and $15 \%)$ were submitted to the consistency experiment by the Flow- Table [27]. According to Figure 2, it is possible to see the behavior of HEMC, pA and pAVE admixtures in mortar consistency. All samples have a reference consistency of $216 \mathrm{~mm}(0 \%$ admixture $)$.

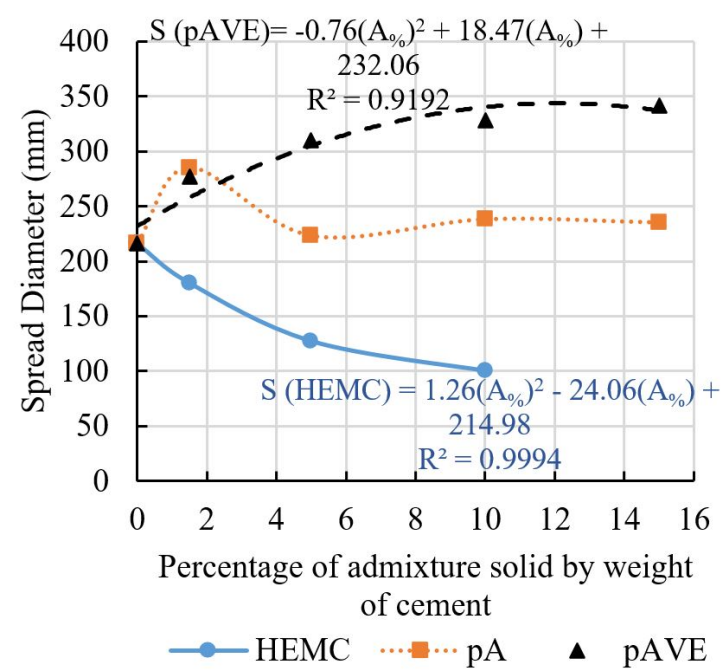

Figure 2. Flow-Table results.

First, it is possible to observe in Figure 2 that cellulosic (HEMC) was responsible for a representative drop (50\%) in consistency. Higher the concentration of this admixture, drier the mixture was found [2], [32], [33]. So, it was impossible to carry out the experiment for $15 \%$ dosage of HEMC, as the mortar was extremely dry and had a stick aspect, the mechanical mixer used was unable to complete the mixing procedure proposed in item 2 . The spread diameter for $10 \%$ of HEMC was the same of the cone $(100 \mathrm{~mm})$, as the mixture did not spread with the 30 falls of the table (Figure 3).

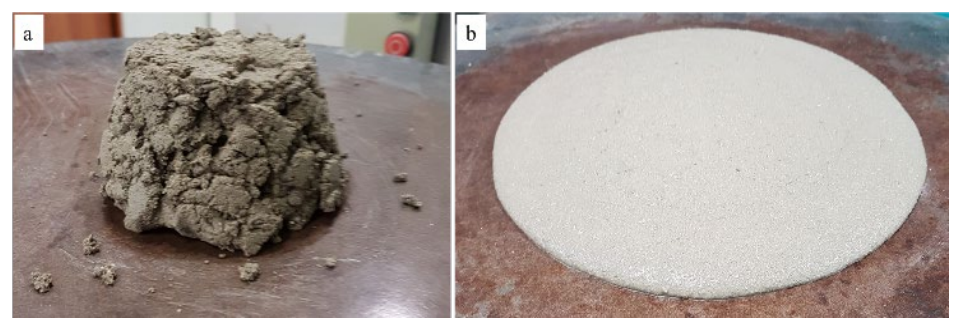

Figure 3. Spread Diameter HEMC - 10\% (a), pAve - 10\% (b).

Cellulose ethers can act through three mechanisms: adsorption, association and entanglement [34]. However, it is noticeable that the most significant effect of this admixture is the association with water molecules, generating a mortar gel, and significantly increasing the consistency and cohesion of coating mortars as found in the bibliography [5], [6], [35], [36]. This mechanism was verified in the mixing process, in which the mortar had a sticky aspect (high cohesion), and it was difficult to mix in high dosages of HEMC.

Through the results of the mixtures with pAVE (Figure 2) it was possible to see that the spreading diameter increases considerably (36.48\%) with the increase of the concentration of the admixture, reaching up to $342 \mathrm{~mm}$ with $15 \%$ dosage, being its behavior contrary to HEMC admixture, which can be seen in Figure 3, where both have the same concentration. 
Such behavior justifies the use indicated in the bibliography [6], [21], [22], [35], demonstrating performance also as a plasticizer, increasing the consistency. It is noticed that this admixture acts through the entanglement of polymeric molecules, which in high concentrations, and suffering the stresses of the spreading table, fluidized the material [37], explaining the increase in the spreading diameter with the higher dosage of the admixture. It presented a more pronounced increase of spread diameter $(22 \%)$ up to $1.5 \%$ of admixture, decreasing its rate of fluidization after this concentration. The behavior of this type of admixture is associated with entanglement with water molecules, increasing the initial apparent viscosity that tends to disappear when subject to stresses, fluidizing the material and increasing its consistency [6], [35].

The admixture pA did not significantly influence the consistency of mortars. Disregarding the outliers' values, it is possible to observe a linear behavior close do $240 \mathrm{~mm}$, as seen in Figure 2. It appears that despite the supplier [23] disclosing improvements in workability it was not observed in the results, not showing a significant variation. The acrylic polymer (pA) is classified as a Superabsorbent polymer (SAP), which has the association retention mechanism, by trapping surrounding water in its structure, which is gradually released during the curing process. This association leads to the formation of a gel and increase the viscosity of the mixture [6], [37]. Despite these characteristics, this behavior was not observed in this study, and the consistency remained practically unchanged, similar to the mixture without admixture, as observed by João [38].

The consistencies showed great variability among the admixtures and dosages used considering the amount of water fixed in the mixture. According to Bauer et al. [39] Flow-Table method has great variability, and therefore mortars with spreading diameter between $190 \mathrm{~mm}$ and $290 \mathrm{~mm}$ by this method would be within a range suitable for use as coating mortar. Analyzing the results by this interval [39], it is observed that for concentrations below about $1 \%$ of HEMC, $3.5 \%$ of pAVE and all pA concentrations the mortar would be suitable for use as a coating. The adequate consistency for external coating mortars according to Santos et al. [24], must have spread diameter of $260 \pm 10 \mathrm{~mm}$. The consistencies that reached closest to this range is up to $1.5 \%$ of pAVE, and for the cellulosic, the value of $1.5 \%$ still has a low spread diameter $(180 \mathrm{~mm})$ generating dry mortars. For this reason, it is recommended to study lower dosages of HEMC to verify this behavior. Thus, to achieve the desired consistency for external coating proposed, the lowest dosages of all polymers used are the most suitable.

\subsection{Water retention}

Figure 4 shows the behavior of each admixture tested relating to water retention measured according to NBR 13277 [28]. The water retention property in mortars is particularly important due to the suction of water by the substrate because the coating mortar that loses a lot of water will not have enough water to react with the cement, compromising the adherence [40] due to the high retraction and the promotion of a powdery coating.

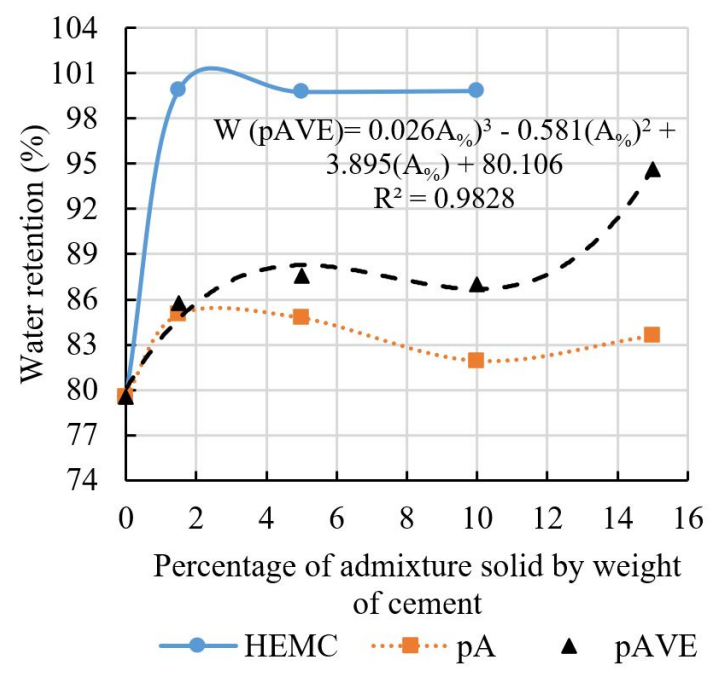

Figure 4. Water retention results 
It is observed that all mortars obtained a result higher than the reference (79.5\% of retention). HEMC cellulosic obtained the highest water retention results in comparison to the other compounds, samples already showed high water retention $(99.9 \%)$ with $1.5 \%$ of this admixture, and the highest concentrations $5 \%, 10 \%$ and $15 \%$ maintained the standard presented with $1.5 \%$. It is noteworthy that the sample with $10 \%$ of admixture were extremely dry, due to the formation of a gel that significantly increased the consistency and cohesion of the coating mortar as verified in bibliography [5], [6], [35], [36]. Thus, the result presented $100 \%$ retention due to dry consistency, and this property could not be measured by the Flow-Table, as it did not present any spread with table drops. However, it is important to emphasize that extremely high-water retentions must be studied with caution, case of HEMC, as values above $96 \%$ may be unsuitable for the mechanical adherence of the mortar, since the substrate will not be able to absorb the necessary water for anchoring reactions [41], as the retention mechanism would be predominant over the absorption of the substrate. Thus, for a complete analysis of the influence of the cellulose ether retention, an analysis is recommended between results of tensile bond strength versus water retention, varying the type of admixture used and its concentration (less than that tested in this work).

PAVE was the second compound with the highest retention results, this behavior was associated with the interlacing mechanism of water retention, even with the fluidity presented on Flow-Table. It was observed an increase in water retention from $0 \%$ to $1.5 \%$, where the results stabilize at approximately $86.5 \%$, then continue to grow at $15 \%$ concentration, reaching $94.6 \%$ of water retention. As seen in Figure 3, the sample was fluid and even so presented high water retention. This demonstrates that the increase in the concentration of pAVE is directly related to the increase in the water retention and consistency, due to the plasticizer effect of the admixture.

With the water retention of acrylic polymer, it is possible to see that this admixture did not presented a similar behavior with any of the other samples, being its highest result $85 \%$ at $1.5 \%$ concentration, presenting a little loss of water retention with the increase of concentration of $\mathrm{pA}$. Lower water retention is associated with non-variation of spread diameter in Flow-Table. Despite being a superabsorbent polymer (SAP), the effective action of its mechanism by the increase of viscosity of the sample was not observed. This affected the water retention as this mixture did not trapped such water as the other mixtures. However, despite this, it is observed that $\mathrm{pA}$ obtained greater retention compared with the reference mortar, without admixture.

Thus, this study observed that the results of retention using various compounds can vary from $100 \%$ to $85 \%$. Due to the older methodology used and the great variability of results, the question about the validity of the method arose. Do Ó and Bauer [42] established that with the methodology used in NBR 13277 [28], there is the confinement and gravitational weight of the sample preventing water loss, and thus this method would present higher water retention results. The authors also established that the water retention analysis should not be made punctual on time, right after dosing it, but performed over time until the stabilization is verified. Thus, water retention, using the method adopted, was measured again for mixtures of $1.5 \% \mathrm{pA}$ (lowest results) and a mixed mortar, mixture was measured at times 0 , 15, 30 and 60 minutes with the intention of verifying the variation of the results over time (Figure 5).

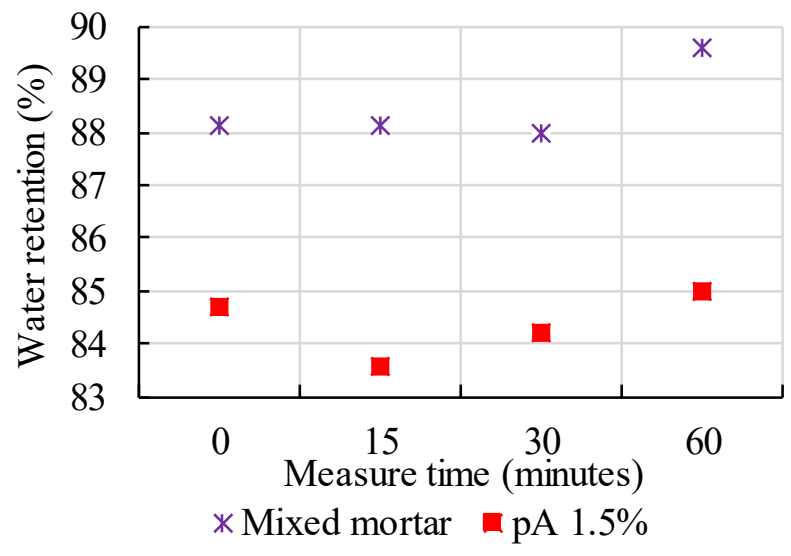

Figure 5. Water retention: mixed mortar x pA 1.5\%, measured through time. 
Figure 5 showed that results did not present a large variation of water retentions through time. The results, in both studied samples, only obtained a slight increase when they were measured after 1 hour of placement at the mold, which means that the mortar was already drying, and because of that the filter was not able to suck the water, inducing the test to indicate greater water retention. Since, if the 60 minutes result was removed, it is feasible to approach the results on a straight line. Thus, from the results obtained, it is concluded that time does not influence the measures taken and that they could be done right after the mortars were dosed, without compromising the results.

Due to the questioning of the method used presents inferior results compared with the retention of the suction method of NBR 13277 [28] revision of 2005. Through bibliographic review it was verified that Forti [43] and Hermann and Rocha [44] obtained inferior results for mixed mortar (78.05\%) and mortar with admixture (52.2\%) than those obtained by the old study standard (Figure 5). Therefore, the results presented are adequate according to the method, and to establish a comparison with other studies, it is important that they have been carried out by a similar method to the one employed in this research [45].

With all the questions exposed and the results obtained, it can be seen that the studied admixtures can have high retention depending on the chemical type used [13], [16], and they can have great variability of results between them, varying according to the chemical used and its characteristics.

\subsection{Fresh state density and air entrained}

Figure 6 presented the results of fresh density of the studied samples. It is observed that the results of HEMC showed the greatest drop in density in relation to the $0 \%$ reference $\left(1950 \mathrm{~kg} / \mathrm{m}^{3}\right)$, approximately $35 \%$ decrease, density rise a little and established around $1554 \mathrm{~kg} / \mathrm{m}^{3}$. Mortars with cellulosic are known for their low density [17], similar to that obtained in comparison to other samples. In this property (Figure 6), it was not possible to establish a behavior equation of HEMC, since all proposed equations had different behavior from that presented by data. In addition, Santos [46] established that a mortar suitable for application at external coatings must have a density in fresh state greater than $1600 \mathrm{~kg} / \mathrm{m}^{3}$, so that all results presented are below the proposed limit of suitability.

PAVE, unlike HEMC, presented the highest densities among the three admixtures studied. It is observed through the consistency presented by the mixture that the fluidization of the mortar resulted in a better particle packing, favoring a better densification and a higher fresh density. It presented similar result to the $0 \%$ reference sample $\left(1950 \mathrm{~kg} / \mathrm{m}^{3}\right)$. The results are close to $1900 \mathrm{~kg} / \mathrm{m}^{3}$, only at $1.5 \%$ concentration of pAVE that this behavior is not seen, obtaining $1700 \mathrm{~kg} / \mathrm{m}^{3}$. Similar to HEMC, it was not possible to approach the results with a tendency curve.

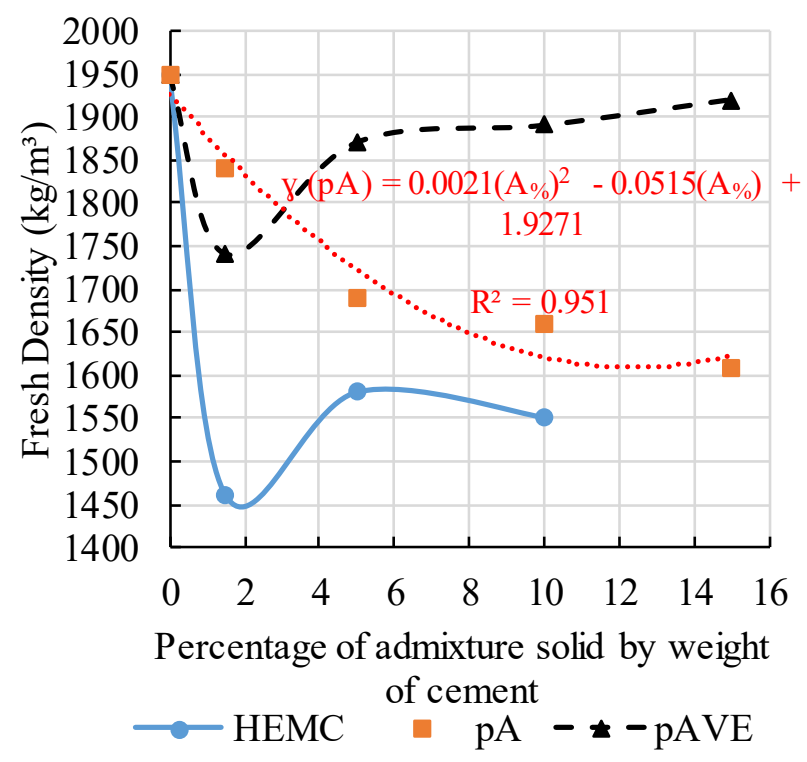

Figure 6. Fresh density results. 
PAVE tends to incorporate more air, as seen in Figure 7, at lower concentrations reducing density, while at higher concentrations the plasticity gain tends to maintain density. PA admixture obtained intermediary results when compared with the other polymers used, and it also has a more pronounced density decrease between $0 \%$ and $5 \%$, and the decay rate begins to decrease above $5 \%$ of its concentration. This decrease is linked to the greater air incorporation promoted by pA, which, by releasing the water associated in the polymeric chain, generates spherical pores [6]. However, when an equilibrium at consistency is observed, above $5 \%$, it is also observed that density stabilizes, as consistency was not strongly influenced, density followed the same behavior.

Making a parallel between density in the fresh state, Figure 6, and consistency, Figure 2, it is possible to note that the mixture with the lowest spread diameter (HEMC), and the mixture with the greatest spread diameter (pAVE) were those that obtained the lowest density and the highest density respectively. And pA, as there was no great variation in spread diameter, the consistency remained with an intermediate result compared with others samples. This behavior is associated with the facility of sample densification in the molds, when the mixture is dry, with low spread diameter, it will be more difficult to densify it, and because of this more voids could appear, thus decreasing sample density.

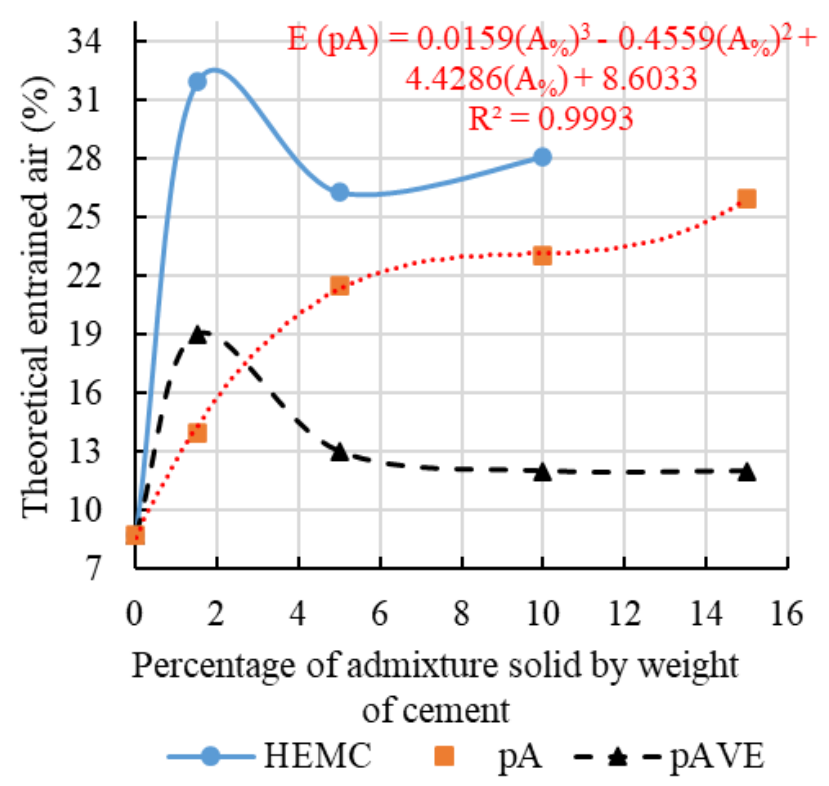

Figure 7. Theoretical entrained air results.

The incorporated air, as mentioned in item 2 , was obtained theoretically through the relationship between the density in the fresh state and the proportion of the materials versus the specific mass of the materials used (cement, sand, admixture and water), with this procedure the results presented in Figure 7 were obtained.

As expected, due to the results obtained in fresh state density (Figure 6), HEMC cellulosic was the one that incorporated more air into the mixture, reaching an expressive result of $32 \%$ at $1.5 \%$ dosage, around $350 \%$ higher than reference $(9 \%$ of incorporated air). However, with the increase in concentration, there is a slight drop in the incorporated air to $26 \%$. In $10 \%$ concentration, the result start to increase again. This variation may be associated with the difficult in molding its samples, because the mixture was extremely dry and with high cohesion because of forming a Strong gel and/or strengthening gel formed by the mineral particles presented in the mortar [8]. Cellulose ethers are well known for incorporating air into the mixture [2], and due to this it obtained higher air incorporation compared with the other compounds. HEMC did not possess a trend behavior it was not possible so establish a curve for its air incorporation. However, it is possible to see a correlation between the results of HEMC in water retention, Figure 4, with theoretical air incorporation, Figure 7 as, more the mixture incorporates air, greater the water retention capacity [8], obtaining high water retention (above 94\%) with the air incorporation above $25 \%$. However, the behavior relating the highest retention to the highest theoretical incorporated air is not valid for pAVE or pA. So, even the action mechanisms were similar, they act differently in each sample. 
Admixture pAVE incorporated more air with $1.5 \%$ concentration (19\%), as seen in HEMC, but the incorporated air decreased with the increase of its concentration, above $5 \%$, stabilizing the result by around $12 \%$ of incorporated air. Even with a $15 \%$ concentration of the admixture, which achieved a retention peak of $95 \%$, the incorporated air remained at $12 \%$. Analysing the theoretical incorporated air, it is observed a similar behaviour to fresh state density, however inverse, since this result is obtained through this parameter. It is also possible to associate the incorporated air with the consistency increase of pAVE, its highest content of incorporated air was obtained when the data had a more accentuated growth (1.5\%), after this value it is noticed a stabilization of incorporated air and consistency. As already explained the higher content of incorporated air in HEMC, despite the mixture being dry, it was due this reason and the difficult of densification.

pA admixture, despite not having influenced the consistency, was responsible for the greater incorporation of air in the mixture, explaining the decrease in density. For mixtures with a higher content of incorporated air, the Flow-Table method may not evaluate the consistency adequately, as the air is able to absorb the impacts generated by the table, presenting the same consistency for a better workability [39], explaining the equilibrium of consistency presented by pA. From the pA behaviour, it is observed that it was the only compound that presented a more uniform growth with the variation of concentration of the Polymer. The air incorporation increases more sharply up to $5 \%$ of utilization $(22 \%$ of incorporated air), and continues to increase, with a lower rate, up to $15 \%$ ( $26 \%$ of air incorporated). Presenting, between the three polymers studied, an intermediate air incorporation. These being a more significant effect of air incorporation of this Polymer, this being a basic condition to reduce density, however without affecting the consistency and water retention, by the evaluated methods.

\subsection{Hardened state density and porosity}

Figure 8 presents the results of hardened state density of the samples, being the reference $1800 \mathrm{~kg} / \mathrm{m}^{3}$. In general, the results presented are similar to those presented in the fresh state density (Figure 6), as the two properties are linked, the difference between them being characterized by matrix stiffening and evaporation of water, which favours density decrease of the samples. It is also noted that the density decrease in the hardened state compared with the fresh state is a behaviour presented by all samples, presenting little differences of behaviour, associated with the secondary effect of air incorporation (Figure 7), generating greater porosity (Figure 9) and thus reducing the density of the samples.

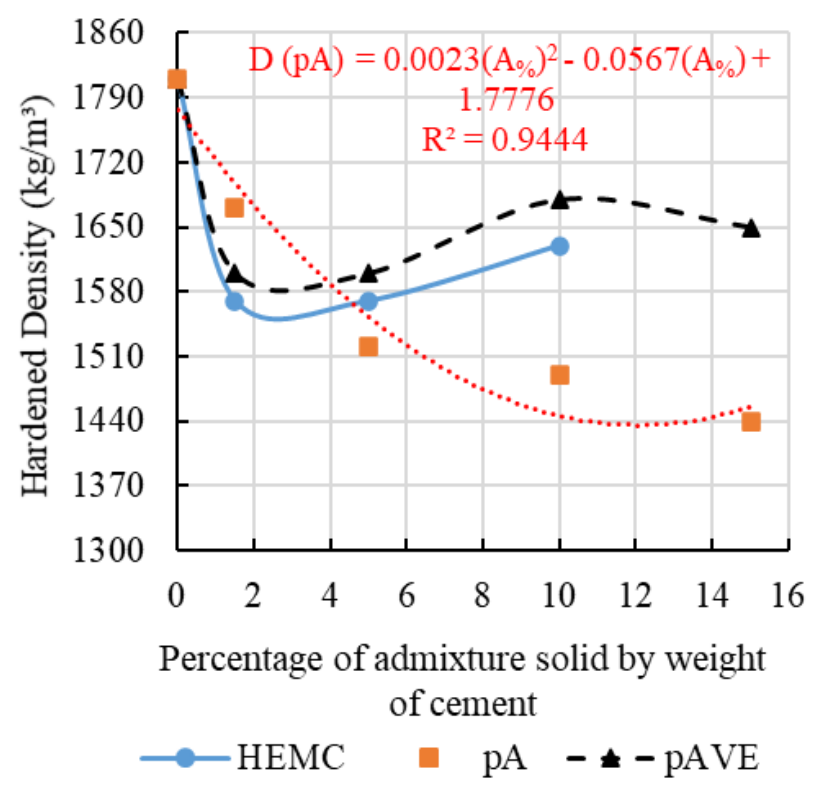

Figure 8. Hardened Density results

HEMC results showed a variation of its behaviour compared with density in the fresh state, sample had decrease of $13.33 \%$ of its density, less accentuated until $1.5 \%$ concentration, and subsequently, the results increase, except in the last concentration studied (10\%). Until 5\% concentration of HEMC, it is responsible for the lowest sample densities, 
after this interval pA obtained the lowest results. It is believed that HEMC associated with the water, reducing consistency (Figure 2) due to the formation of a gel that traps the water, generating isolated pores, and due to the difficult of densification because of the drier consistency of mortars. This trapped water evaporated after a while, being responsible for the decrease of this property. Polymer pAVE presented similar behaviour with HEMC until 5\% of its concentration, presenting intermediary results of density in the hardened state when compared with the other polymers, and above this percentage it presented the highest hardened densities among all the samples. It is observed that, as well as the fresh state density of pAVE, the hardened state density presented a considerable decrease between $0 \%$ and $1.5 \%$ and above this concentration the results fluctuates between $1600 \mathrm{~kg} / \mathrm{m}^{3}$ and $1700 \mathrm{~kg} / \mathrm{m}^{3}$ (in other words, it remained constant), $11 \%$ below the result of fresh state density. This result is justified due to the greater air incorporation (Figure 7) at lower concentrations of this Polymer, reducing density, while at higher concentration the gain in plasticity tended to maintain density due to the better densification and less demand for kneading water. Polymer pA maintained the same behaviour for density in the hardened state (Figure 8), which it presented in the fresh state density (Figure 6). There was observed a density decrease of $11 \%$, at $15 \%$ concentration of the Polymer, when density in the fresh state and hardened state are compared. Whit up to $5 \%$ of this polymer, it is responsible for the highest results of density in the hardened state, and with concentration above 5\% it presented the lowest results of hardened density. The effect of incorporating air promoted by the admixture $\mathrm{pA}$ becomes more evident in this property and in the porosity, generating proportional decrease of density with the increase in its content.

The behaviour of the samples in density in the hardened state follows the same behaviour presented in density in the fresh state, only HEMC admixture that presented a smaller variation between the fresh and the hardened density than the other admixtures, this is due to the samples already presented low density because of the voids left by densification, as it was dry, because of this there was less variation in density in the hardened state.

All the results found for density in the hardened state characterized mortars suitable for use as external coating, as they have hardened density greater than $1400 \mathrm{~kg} / \mathrm{m}^{3}$ [24].

Theoretical porosity, as well as the air incorporated, were obtained through the relation between density in the hardened state and the specific mass of materials used. In Figure 9, the results of porosity for HEMC, pA and pAVE are presented.

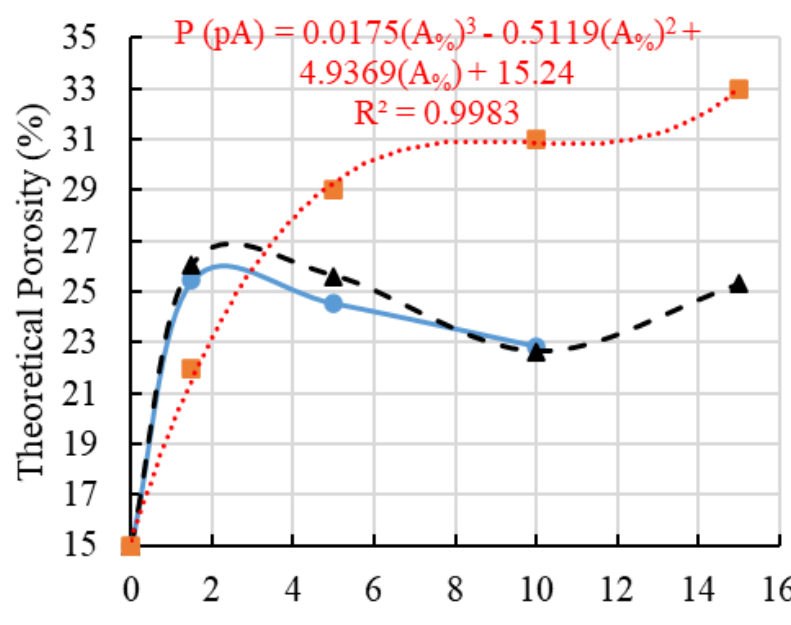

Percentage of admixture solid by weight
of cement

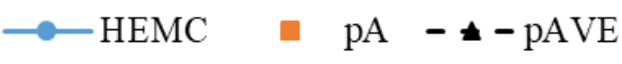

Figure 9. Theoretical Porosity results.

Firstly, when analysing Figure 9, in the HEMC curve all porosities were inferior to the results presented by the theoretical incorporated air, despite the curve maintaining a similar pattern. The porosity had an accentuated increase compared to the reference $0 \%$, and after $1.5 \%$ of its concentration, the results slowly decay. This decay in porosity in relation to the incorporation of air may be associated with a better use of the kneading water retained by the Polymer 
in the hydration of cement compounds, which filled the previously empty voids. Due to the exposed, the samples with HEMC admixture, in general, obtained the reduction of theoretical porosity.

Mortars with pAVE obtained similar porosity with HEMC, being pAVE responsible for a greater porosity when compared to HEMC, reaching $26 \%$ of porosity with $1.5 \%$ of its concentration. Afterwards, the results decrease up to $10 \%$ of polymer. In other words, the results above $5 \%$ of its concentration, varied between $23 \%$ and $26 \%$ of porosity, not having a data stabilization, similarly to that presented in the incorporation of air property.

Both pAVE and pA showed an increase in porosity compared to the theoretical incorporated air, these results are associated with the exit of the water from the sample in the fresh state, increasing the porosity in the hardened state. However pAVE and HEMC stabilize the porosity around $25 \%$, pA shows a density increase with the increase of admixture content, as well as the theoretical incorporated air, it is noticed again that despite the incorporated air is responsible for the improvement of workability [32], [47], [48], these improvement was not measured by the Flow- Table method. Comparing pA with HEMC and pAVE, it is possible to notice that pA is the only one with porosity increase, indicating excessive water in the mixture, which did not occur with the other samples. It is important to highlight that mixtures with excessive porosity may have their mechanical and durability properties affected and therefore should be used with caution.

Due to the large variations in the results, it was not possible to establish a prediction equation of the theoretical porosity for HEMC and pAVE. However, it is possible to establish a prediction curve for $\mathrm{pA}$, with $\mathrm{r}^{2}$ of 0.99 . Where, it is possible to see a less pronounced increase in porosity up to $5 \%$ of its utilization, compared to the other polymers. After this concentration, the porosity continues to increase at a less expressive rate, reaching a maximum result of $33 \%$ with $15 \%$ concentration. These higher results, when compared to air incorporated, obtained in Figure 9, can be associated with the excessive water evaporation during the hydration process of the mixture.

\subsection{Compressive strength}

The mechanical strength of samples was verified thorough simple compression of samples with 28 days. Results of three polymers versus their concentrations are presented in Figure 10.

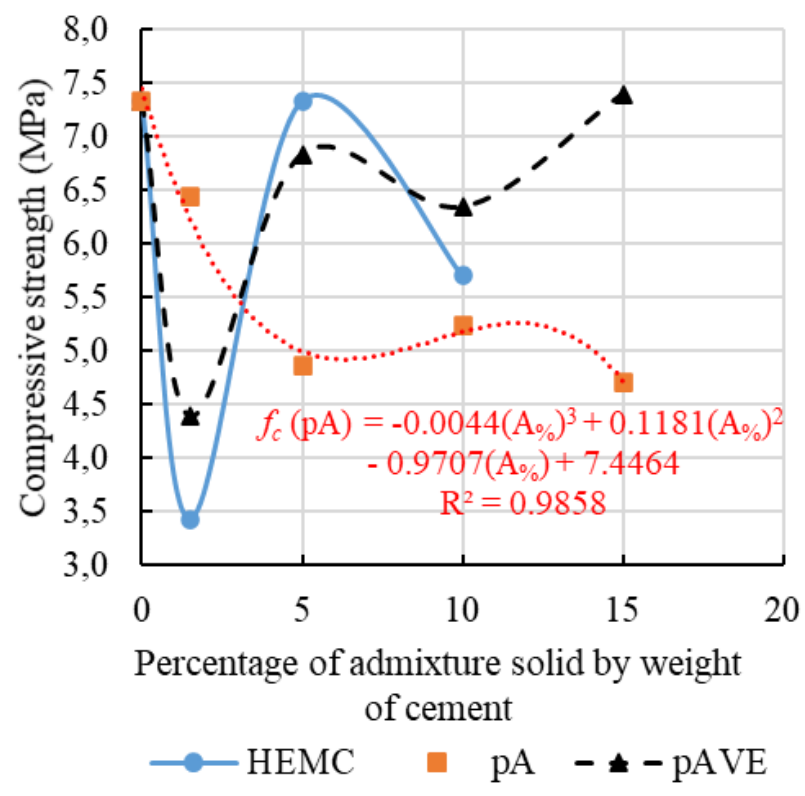

Figure 10. Compressive strength Results.

Analysing HEMC behaviour, it is possible to observe a sharply increase of porosity up to $1.5 \%$ of its concentration, which was responsible for a compression decrease (3.4 MPa) comparing with reference $0 \%$ ( $7.3 \mathrm{MPa}), 210 \%$ smaller. However, the result start to increase in 5\% concentration matching reference result, but after, it decreased one more time. Due to this behaviour, it is not possible to stablish a prediction equation that fit the data. When theoretical porosity 
(Figure 9) decreased in 15\%, compressive strength also decreased, this could be associated to an inefficient moulding of samples, as they were dry, making densification difficult.

As seen for HEMC, it was not possible to stablish a prediction equation for pAVE due to variability of results. Firstly, the results suffer a sharply decrease of compressive resistance (4.4 MPa), compared to the reference sample, with $1.5 \%$ concentration. After this concentration, the result increase expressively reaching $6,84 \mathrm{MPa}$ in $5 \%$ polymer use. It is observed that even pAVE obtained a high porosity $26 \%$ in $5 \%$ of its concentration, this was the percentage that favoured mechanical resistance, in other words, when it obtained the highest result. For all exposed, HEMC and pAVE have their better concentration in 5\% when compressive strength is analysed.

At last, Polymer pA obtained an inverse behaviour compared with theoretical porosity, being the porosity increase responsible for mechanical decrease, as its voids acted as points of tension accumulation in mortar [6], contrary to what happened in $5 \%$ of utilization of the two other polymers, as mentioned. The porosity decreased the growth rate between $5 \%$ and $10 \%$ concentrations, and because of this the compressive strength slightly increase, presented in Figure 10 . As the results presented a pattern it was possible to stablish a prediction equation with $\mathrm{r}^{2}$ of 0.98 .

It is important to notice that porosity up to $25 \%$ still corresponds to an adequate value, because it did not compromise the compressive strength. However, above this value, as seen with Polymer pA, the porosity compromised the mechanical resistance.

\section{CONCLUSIONS}

Due to all exposed, it is concluded:

- Consistency is reduced by HEMC, due to the association mechanism, where attraction forces between polymeric molecules may arise restricting the movement of water molecules, generating a gel and transforming the mortar on a dry material, making it impossible to conduct the experiment beyond $10 \%$ concentration. pAVE acted through the interlacing mechanism of the polymeric chains, which tends to increase viscosity, but in higher concentrations and the stresses of Flow table, fluidized the mixture. Due to this, pAVE also acted as a plasticizes in the mixture, increasing the spread diameter with the admixture increase content. Consistency almost did not change with $\mathrm{pA}$ admixture, despite being a superabsorbent polymer that usually increase viscosity of samples, but at Flow-Table experiment that was not observed.

- The water trapping mechanism can also be seen in water retention experiment in which HEMC obtained the maximum retention with $1.5 \%$ of its concentration. PA improved its water retention with concentration increase, reaching up to $94 \%$ (increase of $19 \%$ ). It is important to highlight that HEMC high water retention result is associated with the dry mortar, due to the gel formation. Although pAVE fluidized the material, it presented increase in water retention, reaching maximum water retention with $15 \%$ of its concentration. PA presented the lowest water retention results compared with other samples, however it still presented higher results compared with reference, being appropriate its use as a retainer. Extremely high-water retention in mortars, presented by the other samples, must be carefully studied so it can not affect the mechanism of mechanical adherence to the substrate. It was found, that different from bibliography, it is not necessary to make several retention measures through time, using the standardized weight method, since the measure near the time of mixture preparation is suitable to measure this property.

- The difficult to mould dry mortars as the ones with HEMC, due to the gel formation because of the interlacing mechanism of the admixture generated voids in the matrix, resulting in a higher air entraining content and density decrease in the fresh state. PAVE action resulted in a more fluid mortar, allowing better accommodation of materials and densification of samples, maintaining density and entrained air content stable even with admixture increase. If consistency was maintained, water content could be reduced, increasing density and decreasing entrained air, corroborating that this admixture could also be used as a plasticizer. Samples with pA presented the highest increase rate of theoretical entrained air, due to these highest results the Flow-Table failed to measure the consistency variation, since the incorporated air is known to improve workability.

- It is noticed that until 5\%, admixtures presented similar behaviour between hardened state density and fresh state density. Beyond this concentration, pA reduced density's result. Similar behaviour, but inverse, can be seen in the porosity, demonstrating that $\mathrm{pA}$, commonly used in stabilized mortars tends to increase mortars' porosity if it is used at higher concentrations, justifying density decrease. HEMC and pAVE despite influence consistency differently, presented similar hardened density and porosity with approximately porosity of $25 \%$. However, samples with pA presented exponential increase, which it is not good because higher porosities are harmful to mechanical properties. 
- The mechanical behaviour was more influenced by the availability of water to hydrate and by the porosity, maintaining the results for HEMC and pAVE above $5 \%$ of its concentration, stabilizing the results in approximately $25 \%$. Lower concentrations of these admixtures presented lower results compared to the reference, showing the inefficiency of its individual use.

- To obtain more satisfactory results, it is adequate to reduce water consumption with pAVE or to dose a plasticizer together with HEMC. PA showed to be inadequate in higher concentrations for use in the coating mortars analysed. Above $5 \%$ of pA concentrations, it had porosity greater than $25 \%$, impairing the compressive strength of samples. Its use must be done carefully in adequate dosages, it is recommended to reduce the amount of water with the increase of PA's concentration, maintaining consistency, decreasing porosity and thus increasing mechanical strength.

These dosages adjustments tend to improve the mechanical behaviour and the other properties. The present research concluded that several admixtures that could be used as a water retainer can have several mechanisms of action that will influence mortars in different ways. Concentration and composition of admixtures must be studied according to the desired properties in the mortars.

\section{ACKNOWLEDGEMENTS}

The authors acknowledge the Brazilian agencies: National Council of Scientifical and Technological Development (CNPq), Coordination of Improvent of Higher Education Personnel (CAPES) and Minas Gerais Research Support Foundation (FAPEMIG) for the support given to this study.

\section{REFERENCES FORMATS}

[1] A. T. Souza, L. A. Riccio, G. C. Laquini, and W. J. Santos, "Behavior of mortar coatings subjected to extreme conditions: Lack of curing and no substrate moistening," Int. J. Sci. Eng. Investig., vol. 7, no. 75, pp. 53-59, Apr 2018.

[2] H. Paiva, L. Silva, J. Labrincha, and V. Ferreira, "Effects of a water-retaining agent on the rheological behavior of a single-coat render mortar," Cement Concr. Res., vol. 36, pp. 1257-1262, 2006, http://dx.doi.org/10.1016/j.cemconres.2006.02.018.

[3] R. W. Y. Zhao, C. Tuan, and A. Xu, "The influence of water/cement ratio and air entrainment on the electric resistivity of ionically conductive mortar," Materials (Basel), vol. 12, no. 7, pp. 1125, 2019, http://dx.doi.org/10.3390/ma12071125.

[4] A. G. Magalhães et al., "The Influence of the water/cement ratio in the open porosity and in the carbonation front advancing in cementitious matrix composites," Appl. Mech. Mater., vol. 864, pp. 313-317, 2017, http://dx.doi.org/10.4028/www.scientific.net/AMM.864.313.

[5] L. Patural, P. Marchal, A. Govin, P. Grosseau, B. Ruot, and O. Devès, "Cellulose ethers influence on water retention and consistency in cement-based mortars," Cement Concr. Res., vol. 41, no. 1, pp. 46-55, 2011, http://dx.doi.org/10.1016/j.cemconres.2010.09.004.

[6] H. Paiva, L. Esteves, P. Cachim, and V. Ferreira, "Rheology and hardened properties of single-coat render mortars with different types of water retaining agents," Constr. Build. Mater., vol. 23, no. 2, pp. 1141-1146, 2009, http://dx.doi.org/10.1016/j.conbuildmat.2008.06.001.

[7] S. W. do Ó and M. J. A. Salles, "Influência do aditivo retentor de água nas propriedades reológicas de argamassas de revestimentos," in XI Enc. Nac. Tecnol. Ambient. Constr., Florianópolis, SC, Brasil, 2006.

[8] M. Cappellari, A. Daubresse, and M. Chaouche, "Influence of organic thickening admixtures on the rheological properties of mortars: Relationship with water-retention," Constr. Build. Mater., vol. 38, pp. 950-961, 2013, http://dx.doi.org/10.1016/j.conbuildmat.2012.09.055.

[9] A. T. Souza, C. A. Carvalhais, and W. J. Santos, "Analysis of chemical admixtures combination on coating mortar using Simplex network method," Constr. Build. Mater., vol. 239, 2020, http://dx.doi.org/10.1016/j.conbuildmat.2019.117796.

[10] A. T. Souza, C. A. Carvalhais, and W. J. Santos, "Comparativo entre argamassas aditivadas e mista: análise dos aditivos incorporador de ar, retentor de água e plastificante," in VI Congr. Eng. Civ., Juiz de Fora, Brasil, 2019.

[11] M. Gołaszewska, J. Gołaszewski, G. Cygan, and J. Bochen, "Assessment of the impact of inaccuracy and variability of material and selected technological factors on physical and mechanical properties of fresh masonry mortars and plasters," Materials (Basel), vol. 13, no. 6, pp. 1382, 2020, http://dx.doi.org/10.3390/ma13061382.

[12] J. Pourchez, P. Grosseau, R. Guyonnet, B. Ruot, "HEC influence on cement hydration measured by conductometry," Cem. Concr. Res., vol. 36, vol. 9, pp. 1777-1780, 2006, https://doi.org/10.1016/j.cemconres.2006.06.002.

[13] J. Pourchez, B. Ruot, J. Debayle, E. Pourchez, and P. Grosseau, "Some aspects of cellulose ethers influence on water transport and porous structure of cement-based materials," Cement Concr. Res., vol. 40, no. 2, pp. 242-252, 2010, http://dx.doi.org/10.1016/j.cemconres.2009.09.028. 
[14] A. T. Souza, R. B. Caldas, P. Ludvig, and W. J. Santos, "The effects of mixture's components on the mechanical properties and durability indicators of mixed mortar using simplex network method," Constr. Build. Mater., vol. 249, 2020, http://dx.doi.org/10.1016/j.conbuildmat.2020.118740.

[15]W. J. Santos et al., "Study of the effects of excessive cement or lime in mechanical properties and durability of the mortar coating," Int. J. Develop. Res., vol. 9, no. 9, pp. 29923-29927, 2019.

[16]A. L. Oliveira, B. P. Corrêa, I. F. R. Ribeiro, R. A. Souza, and L. M. L. Calçada, "Influence of water-retaining cellulose ethers on the properties of bedding mortar used in concrete structural masonry," Ambiente Constr., vol. 15, no. 3, pp. 57-59, 2015. https://doi.org/10.1590/s1678-86212015000300026.

[17] A. Izaguirre, J. Lanas, and J. Álvarez, "Characterization of aerial lime-based mortars modified by the addition of two different waterretaining agents," Cement Concr. Compos., vol. 33, no. 2, pp. 309-318, 2011, http://dx.doi.org/10.1016/j.cemconcomp.2010.09.008.

[18] O. Z. Hua, M. B. Guo, and J. S. Wei, "Influence of cellulose ethers molecular parameters on hydration kinetics of Portland cement at early ages," Constr. Build. Mater., vol. 33, pp. 78-83, 2012, http://dx.doi.org/10.1016/j.conbuildmat.2012.01.007.

[19]Dow, WALOCEL ${ }^{\mathrm{TM}} M K X 60000$ PF 01. California: DOW, 2020.

[20] Wacker, VINNAPAS® 5010 N (GER). Munique: Wacker, 2011.

[21] H. J. Kim, J. Y. Park, H. W. Suh, B. Y. Cho, W. J. Park, and S. C. Bae, "Mechanical Degradation and Thermal Decomposition of Ethylene-Vinyl Acetate (EVA) Polymer-Modified Cement Mortar (PCM) Exposed to High-Temperature," Sustainability, vol. 11, no. 2, pp. 500, 2019, http://dx.doi.org/10.3390/su11020500.

[22] K. A. Khan, I. Ahmad, and M. Alam, "Effect of Ethylene Vinyl Acetate (EVA) on the Setting Time of Cement," Arab. J. Sci. Eng., 2018.

[23] Mc Bauchemie, Centripor Kombi AC (antigo Powermix AC 1000). São Paulo: Mc Bauchemie, 2018.

[24] W. J. Santos et al., "Proposal for a mix design method for coating mortar with artificial crushing sand," Ambient. Constr., vol. 18, no. 1, pp. 225-243, 2018, http://dx.doi.org/10.1590/s1678-86212018000100218.

[25] K. S. Yeon, K. K. Kim, J. Yeon, and H. J. Lee, "Compressive and flexural strengths of EVA-modified mortars for 3D additive construction," Materials (Basel), vol. 12, no. 16, pp. 2600, 2019, http://dx.doi.org/10.3390/ma12162600.

[26] Associação Brasileira de Normas Técnicas. Mixing Water for Concrete Part 1: Requirements, ABNT NBR 15900-1:2009, 2009.

[27] Associação Brasileira de Normas Técnicas. Mortars Applied on Walls and Ceilings - Determination of the Consistence Index, ABNT NBR 13276:2016, 2016.

[28]Associação Brasileira de Normas Técnicas. Mortars Applied on Walls and Ceilings - Determination of the Water Retentivity, ABNT NBR 13277:2005, 2005.

[29]A. T. Souza, "Comparative analysis of mechanical properties and durability, between hydraulic lime mortar coating and additive mortar coating," M.S. thesis, Univ. Fed. Minas Ger., Belo Horizonte, Brasil, 2019.

[30] Associação Brasileira de Normas Técnicas. Mortars Applied on Walls and Ceilings - Determination of the Specific Gravity and the Air Entrained Content in the Fresh Stage, ABNT NBR 13278:2005, 2005.

[31] Associação Brasileira de Normas Técnicas. Portland Cement - Determination of Compressive Strength of Cylindrical Test Specimens, ABNT NBR 7215:2019, 2019.

[32] M. P. Seabra, J. Labrincha, and V. M. Ferreira, "Rheological behavior of hidraulic lime-based mortars," J. Eur. Ceram. Soc., vol. 27, no. 2-3, pp. 1735-1741, 2007, http://dx.doi.org/10.1016/j.jeurceramsoc.2006.04.155.

[33] A. Pierre, A. Perrot, and Y. Guevel, "Cellulose ethers and cement paste permeability," Cement Concr. Res., vol. 72, pp. 117-127, 2015, http://dx.doi.org/10.1016/j.cemconres.2015.02.013.

[34] K. Khayat, "Viscosity-enhancing admixtures for cement-based materials - an overview," Cement Concr. Compos., vol. 20, no. 2-3, pp. 171-188, 1998, http://dx.doi.org/10.1016/S0958-9465(98)80006-1.

[35] E. Knapen and D. V. Gemert, "Cement hydration and microstructure formation in the presence of water-soluble polymers," Cement Concr. Res., vol. 39, pp. 6-13, 2009., http://dx.doi.org/10.1016/j.cemconres.2008.10.003.

[36] J. Pourchez, A. Peschard, P. Grosseau, R. Guyonnet, B. Guilhot, and F. Vallé, "HPMC and HEMC influence on cement hydration," Cement Concr. Res., vol. 36, no. 2, pp. 288-294, 2006, http://dx.doi.org/10.1016/j.cemconres.2005.08.003.

[37] N. J. D. Alves and S. W. do Ó, "Aditivos incorporadores de ar e retentores água," in Revestimentos de Argamassa: Características e Peculiaridades, E. Bauer, Ed., Brasília: LEM/Unb, 2005.

[38] F. A. João, "The influence of superabsorbent polymer in conventional concrete properties," M.S. thesis, Univ. Estad. Sta. Catarina, Joinville, Brasil, 2015.

[39] E. Bauer, G. G. J. Sousa, and E. A. Guimarães "Estudo da consistência de argamassas pelo método de penetração estática de cone," in VI Simp. Bras. Tec. Argamassas/ I Int. Symp. Mortar Tech., Florianópolis, SC, Brasil, 2005.

[40] I. Paes, E. Bauer, H. Carasek, and E. Pavón, "Influence of water transportation inside a mortar/block system on bonding resistance behavior," Rev. Ing. Constr., vol. 29, no. 2, pp. 175-186, 2014. 
[41] A. C. A. Jantsch, "Permeability analysis of ready-to-uso mortars with waterproofing treatment," M.S. thesis, Univ. Fed. Sta. Maria, Santa Maria, Brasil, 2015.

[42]S. W. do Ó and E. Bauer, "Avaliação das metodologias empregadas para determinação da retenção de água em argamassas de revestimento aditivadas," in I Conf. Latino-Amer. Constr. Sustent./ X Enc. Nac. Tec. Ambient. Constr., São Paulo, SP, Brasil, 2004.

[43]E. Z. Forti, "Influence of hydrated lime on the characteristics of the coating mortar carried out on site," Graduation in Civil Engineering, Univ. Vale do Taquari - Univates, Lajeado, Brasil, 2017. [Online]. Available: http://hdl.handle.net/10737/1645

[44]A. Hermann and J. P. A. Rocha, "Feasibility study of the use of modified stabilized mortar for coating without rough cast," Graduation in Civil Engineering, Univ. Tec. Fed. Paraná, Pato Branco, Brasil, 2013.

[45] Association Française de Normalisation. Norme Française: Travaux d'enduits de Mortiers - Partie 1-1: Cahier des Clauses Techniques, NF DTU 26.1 P1-1, 2008.

[46]W. J. Santos, "Development of methodology for determination of coating and settlement mortar," Doctoral dissertation. Univ. Fed. Viçosa. Viçosa, Brasil, 2014. [Online]. Available: https://www.locus.ufv.br/handle/123456789/6865

[47] R. C. O. Romano, D. R. Torres, and R. G. Pileggi, "Impact of aggregate grading and air-entrainment on the properties of fresh and hardened mortars," Constr. Build. Mater., vol. 82, pp. 219-226, 2015, http://dx.doi.org/10.1016/j.conbuildmat.2015.02.067.

[48] V. Kontogiorgos, H. Vaikousi, A. Lazaridou, and C. G. Biliaderis, "A fractal analysis approach to viscoelasticity of physically crosslinked barley $\beta$-glucan gel networks," Colloids Surf. B Biointerfaces, vol. 49, no. 2, pp. 145-152, 2006, http://dx.doi.org/10.1016/j.colsurfb.2006.03.011.

Author contributions: ATS: conceptualization, methodology, writing-original draft preparation; CAC: methodology; WJS: conceptualization, methodology, supervision, writing- reviewing and editing.

Editors: Lia Pimentel Sousa, Guilherme Aris Parsekian. 